\title{
O que a literatura científica e os projetos político-pedagógicos revelam sobre a qualidade da educação superior em enfermagem?
}

\author{
What do the scientific literature and the political-pedagogical \\ projects reveal about the quality of higher education in nursing?
}

Polyana de Castro Limeira1', Otília Maria Lúcia Barbosa Seiffert², Lidia Ruiz-Moreno²

${ }^{1}$ Programa de Pós-Graduação de Ensino em Ciências da Saúde, Universidade Federal de São Paulo (UNIFESP) - São Paulo (SP), Brasil. ${ }^{2}$ Centro de Desenvolvimento de Ensino Superior em Saúde (CEDESS), UNIFESP - São Paulo (SP), Brasil.

DOI: http://dx.doi.org/10.7322/abcshs.v40i3.808

\section{RESUMO}

Introdução: $\mathrm{O}$ atual panorama da educação superior em enfermagem configura-se pelo elevado número de cursos, cujos níveis de qualidade requerem questionamento. Com vistas a assegurar que a expansão destes cursos tenha critérios de qualidade, torna-se premente a avaliação do processo de formação. Objetivos: Conhecer a literatura científica acerca do eixo temático 1 (ET1): avaliação da qualidade da educação superior em Enfermagem (QESE) e do eixo temático 2 (ET2): percepção de egressos acerca desta qualidade; compreender os parâmetros de qualidade que embasaram a elaboração de Projetos Político-Pedagógicos (PPP) de cursos de graduação em Enfermagem. Métodos: Pesquisa bibliográfica, por meio de estratégias de busca utilizando combinações entre os termos avaliação, qualidade, Enfermagem, egressos e educação superior; pesquisa documental: análise de PPP de cursos de graduação em Enfermagem do município de São Paulo (SP) que disponibilizam o documento para consulta pública nos sites das instituições de ensino superior. Resultados: Pesquisa bibliográfica: ET1: artigos internacionais, enfoque às competências clínicas (predomínio da visão tecnicista), ausência da concepção de QESE; ET2: artigos nacionais, aspectos com necessidades de melhorias: infraestrutura das IES, interdisciplinaridade, competências gerenciais e de liderança, superação do modelo hospitalocêntrico, dinamização das práticas docentes e a superação da dicotomia teoria e prática. Pesquisa documental: 6 dos 33 cursos de SP disponibilizam publicamente seus PPP; a maioria das preconizações das DCN de Enfermagem esteve presente nos documentos analisados. Conclusão: Os artigos nacionais demonstraram perspectiva ampliada acerca da QESE, condizente com a vertente humanística, ao contrário dos artigos internacionais (visão tecnicista); ínfimo número de PPP disponíveis.

Palavras-chave: educação superior; educação em enfermagem; avaliação educacional; bacharelado em enfermagem; currículo.

\section{ABSTRACT}

Introduction: The current situation of higher education in nursing is marked the high number of courses whose quality levels require questioning. In order to ensure that the expansion of these courses has a quality criteria, the evaluation of the educational process is urgent. Objective: To examine the scientific literature on the thematic axis 1 (TA1): evaluation of the quality of higher education in Nursing (QHEN) and thematic axis 2 (TA2): perception of graduates about this quality; to understand the quality parameters that supported the development of Political-Pedagogical Project (PPP) of undergraduate courses in Nursing. Methods: Bibliographic search, using combinations of the terms assessment, quality, Nursing, graduates and higher education; document search: analysis of the PPP of the undergraduate courses in Nursing in the state of São Paulo (SP) that provide the document for public consultation on the websites of higher education institutions. Results: Literature: TA1: international articles focus on clinical skills (predominance of a technical vision), absence of the concept of QHEN; TA2: national articles, aspects in need of improvement: infrastructure of higher education institutions, interdisciplinarity, managerial and leadership skills, overcoming the hospital-centered model, stimulation of teaching practices and overcoming the dichotomy between theory and practice. Document search: only 6 of the 33 courses in SP provide their PPP; most of the National Curriculum Guidelines for Nursing were present in the analyzed documents. Conclusion: The national papers showed a broader perspective on QHEN, consistent with the humanistic aspect, unlike the international articles (technical vision); very small number of PPP available.

Keywords: higher education; nursing education; educational measurement; baccalaureate nursing education; curriculum. 


\section{INTRODUÇÃO}

$O$ atual panorama da educação superior em enfermagem configura-se pelo elevado número de cursos, cujos níveis de qualidade são dignos de questionamento e de minuciosos estudos. A desenfreada expansão das Instituições de Ensino Superior (IES) de caráter privado iniciou-se a partir da década de 1990 e se intensificou no início do século XXI, em virtude de políticas promovidas pelos governos federais que se sucederam, por meio de mecanismos como isenções fiscais, liberalização dos serviços educacionais, isenção das contribuições previdenciárias de instituições filantrópicas e provimento de bolsas de estudo para alunos com baixo poder aquisitivo ${ }^{1}$. Diante deste cenário de célere privatização/mercantilização do sistema de educação superior, o tema da avaliação da Educação Superior adquire considerável relevância, pois se destina tanto à tentativa de assegurar a qualidade mínima do ensino ofertado, como à necessidade de regular/ controlar a expansão promovida pelo incremento do número de IES de caráter privado ${ }^{2,3}$.

Este artigo é produto de uma dissertação de mestrado, que investigou aspectos relacionados à qualidade da educação superior em Enfermagem, sob a perspectiva dos egressos de cursos de graduação nesta área, bem como as concepções de qualidade presentes na literatura científica e em Projetos Político-Pedagógicos (PPP) dos cursos de Graduação em Enfermagem, com vistas a compreender o arcabouço teórico que fundamentou a elaboração destes documentos.

No presente trabalho, optou-se por focalizar a literatura científica e os PPP dos cursos de graduação em Enfermagem. Tais componentes adquirem indubitável relevância no que tange à detecção das vulnerabilidades, bem como das potencialidades, o que pode subsidiar as ações de promoção da qualidade destes cursos.

O PPP busca uma direção, possui uma intencionalidade e um compromisso definido coletivamente. Desse modo, todo projeto pedagógico é igualmente um projeto político, pois se articula intimamente a um compromisso social e político, coadunando com os interesses da população por possuir o compromisso de formação de cidadãos para um determinado tipo de sociedade ${ }^{4}$.

De acordo com Brito ${ }^{5}$, com a implantação do Sistema Nacional de Avaliação do Ensino Superior (SINAES), em 2004, e o estabelecimento do vínculo entre os eixos dos sistemas, passou-se a considerar como relevante que os PPP dos cursos de graduação sejam fruto de uma construção coletiva dos diversos segmentos atuantes nas IES, buscando adequar os itens preconizados nas DCN ao contexto no qual se insere a instituição. Outrossim, a elaboração do PPP deve atender ao conjunto de diretrizes organizacionais e operacionais orientadoras das práticas pedagógicas do curso, tais como a estrutura curricular, as ementas e o perfil profissional dos egressos consoante às DCN.

Nesta direção, optou-se por problematizar o significado da qualidade da educação superior em Enfermagem, suplantando visões reducionistas e pautadas pelo imediatismo da vertente mercadológica de educação, contribuindo positivamente para futuros projetos, cujo intento seja a melhoria da formação dos enfermeiros e de seus perfis tanto no que tange aos aspectos de caráter técnico-científico como comportamentais/atitudinais. Por conseguinte, viabiliza-se a aplicação cotidiana dos princípios e diretrizes do SUS, rumo à sua consolidação e fortalecimento.

Cabe conceituar qualidade da educação superior, o que por sua vez, requer conhecer a etimologia da palavra qualidade, advinda do termo latino qualitas, que significa essência e denomina o que é mais importante. Segundo o dicionário da língua portuguesa Houaiss $^{6}$, consiste na "superioridade, excelência em qualquer coisa; maneira de ser, boa ou má, de uma coisa; aptidão, disposição favorável; atributo, modalidade, propriedade, virtude".

Diante da polissemia da expressão e da impossibilidade de que se esgote tal discussão, no presente trabalho optou-se por considerar a qualidade da educação superior como aquela que propicia a formação de sujeitos crítico-reflexivos, dotados de senso de responsabilidade social, cidadania, capacidade de transformação da realidade e com a competência formal técnica, relacionada à profissão de escolha, conjugada à competência política ${ }^{7}$.

Este estudo teve por objetivos:

1. analisar as produções científicas acerca da qualidade dos cursos de graduação em Enfermagem;

2. investigar na literatura científica as produções sobre a percepção dos egressos destes cursos acerca da qualidade da educação superior em Enfermagem; e

3. caracterizar os parâmetros de qualidade presentes em PPP de cursos de graduação em Enfermagem da cidade de São Paulo.

\section{MÉTODOS}

\section{Pesquisa Bibliográfica}

A pesquisa bibliográfica é um procedimento metodológico capaz de gerar, especialmente em temas pouco explorados, a postulação de hipóteses ou interpretações que servirão de ponto de partida para outras pesquisas. Implica, ainda, em um conjunto ordenado de procedimentos de busca por soluções, atentando ao objeto de estudo, o que, portanto, não pode ser aleatório ${ }^{8}$.

A pesquisa bibliográfica foi realizada por meio da Biblioteca Virtual em Saúde e da Biblioteca Virtual de Educação em Ciências da Saúde, que concentram as principais bases de dados tanto da área de saúde, como da área de educação voltada para a área da saúde, tais como EDUCA, ERIC, LILACS, MEDLINE, COCHRANE, SCIELO, BDENF, focalizando os artigos nacionais e internacionais, com vistas a atender à necessidade precípua de mapear e conhecer o que há de publicações acerca das áreas temáticas, elucidadas a seguir:

- avaliação da Qualidade da educação superior em Enfermagem: os critérios de inclusão foram: artigos concernentes ao âmbito da graduação em Enfermagem, publicados a partir de 2004, com versão completa disponível, relacionados à temática proposta. Para a busca, foram utilizadas as estratégias descritas no Quadro 1; 
- percepção de egressos acerca da qualidade da educação superior em Enfermagem: os critérios de inclusão foram: artigos concernentes ao âmbito da graduação em Enfermagem, publicados a partir de 2004, com versão completa disponível, relacionados à temática proposta. Para a busca foram utilizadas as estratégias descritas no Quadro 2.

\section{Pesquisa Documental}

De acordo com Lüdke e André9, a pesquisa documental se constitui em uma técnica pertinente, trazendo relevantes contribuições no estudo de alguns temas, pois complementa as informações advindas de outros tipos de estudo ou pode desvendar aspectos novos de um tema. A relevância da utilização de documentos em investigações educacionais como uma técnica exploratória se deve ao fato de que a análise pode apontar problemas que devem ser melhor explorados através de outros métodos.

OsdocumentosestudadosforamosProjetosPolítico-Pedagógicos (PPP) de cursos de Graduação em Enfermagem, selecionados de acordo com os seguintes critérios de inclusão: PPP dos cursos de graduação em Enfermagem das IES situadas no município de São Paulo e que estivessem disponíveis para consulta pública, por meio de seus sites na internet. Ressalta-se que foi mantido o sigilo acerca dos nomes das Instituições de Ensino Superior (IES) e que cada uma delas recebeu pseudônimos, tais como: IES 1, IES 2, IES 3, e assim sucessivamente.

A coleta dos dados e subsequente análise dos PPP foram realizadas tomando por base alguns aspectos norteadores, fundamentados no referencial teórico e tidos como componentes imprescindíveis aos PPP do curso em questão, quais sejam: integração entre teoria e prática; incentivo à pesquisa; uso de metodologias ativas; adoção de avaliação formativa; uso de inovadoras estratégias de avaliação do processo ensino-aprendizagem; adoção da interdisciplinaridade; ensino que promova a aprendizagem significativa, transformando conhecimentos no desenvolvimento de competências e habilidades; relação dialógica entre professor e aluno; formação de profissionais com as seguintes competências: espírito crítico reflexivo; generalistas; com senso de cidadania, responsabilidade social e capacidade de intervenção na realidade; senso de ética; que atendam às necessidades do SUS; autônomos no processo de aprendizagem e na escolha de seus rumos e objetivos e predisposição para autoaprendizagem; preparados para reconhecer a saúde como condições dignas de vida e um direito do cidadão; preparados para compreender a política de saúde no contexto das políticas sociais, reconhecendo os perfis epidemiológicos das populações; que compreendam a natureza humana em suas diversas dimensões e fases evolutivas; preparados para intervir no processo de saúde-doença responsabilizando-se pela qualidade da assistência de enfermagem em seus diferentes níveis de atenção à saúde; preparados para a tomada de decisões, possuindo habilidades para avaliar, sistematizar e decidir a conduta mais adequada; com capacidade de gestão e trabalho em equipe.

\section{RESULTADOS}

\section{Resultados da Pesquisa Bibliográfica}

$\mathrm{Na}$ busca bibliográfica acerca do eixo temático "Avaliação da qualidade da educação superior em Enfermagem", realizada por meio das estratégias de busca, os resultados foram: na busca

Quadro 1: Estratégias de Busca utilizadas no eixo temático "Avaliação da qualidade da educação superior em Enfermagem”. Brasil, 2014

\begin{tabular}{|c|c|}
\hline Estratégia 1 & $\begin{array}{l}\text { (avaliação OR evaluation OR evaluacion OR assessment) AND (qualidade OR calidad OR quality) AND ("graduação em } \\
\text { enfermagem" OR “undergraduate nursing" OR "bacharelado em enfermagem" OR "bachillerato en enfermería") (20\$) }\end{array}$ \\
\hline Estratégia 2 & $\begin{array}{l}\text { (avaliação OR evaluation OR evaluacion OR assessment) AND (qualidade OR calidad OR quality) AND ("graduação em } \\
\text { enfermagem" OR "undergraduate nursing" OR "bacharelado em enfermagem" OR "bachillerato en enfermería") (20\$) AND NOT } \\
\text { "qualidade de vida" }\end{array}$ \\
\hline Estratégia & $\begin{array}{l}\text { (avaliação OR evaluation OR evaluacion OR assessment) AND (ti:qualidade OR ti:calidad OR ti:quality) AND ( } \\
\text { em enfermagem" OR ti:"undergraduate nursing" OR ti”bacharelado em enfermagem" OR ti:"bachillerato en enfe } \\
\text { educação em enfermagem" }\end{array}$ \\
\hline stratégia 4 & $\begin{array}{l}\text { (avaliação OR evaluation OR evaluacion OR assessment) AND (ti:c } \\
\text { enfermagem" OR "undergraduate nursing" OR "bacharelado er }\end{array}$ \\
\hline jia 5 & $\begin{array}{l}\text { (avaliação OR evaluation OR evaluacion OR assessment) AND (qualidade OR calidad OR quality) AND (ti:"graduação em } \\
\text { enfermagem" OR ti:"undergraduate nursing" OR ti:"bacharelado em enfermagem" OR ti:"bachillerato en enfermeria") (20\$) }\end{array}$ \\
\hline
\end{tabular}

Quadro 2: Estratégias de Busca utilizadas no eixo temático "Percepção de egressos acerca da qualidade da educação superior em Enfermagem". Brasil, 2014

\begin{tabular}{|c|c|}
\hline Estratégia 6 & $\begin{array}{l}\text { (egressos OR egressing student OR egresados) AND (qualidade OR calidad OR quality) AND ("graduação em enfermagem" } \\
\text { "undergraduate nursing" OR "bacharelado em enfermagem"OR "bachillerato en enfermería") (20\$) }\end{array}$ \\
\hline ia 7 & $\begin{array}{l}\text { (egressos OR egressing student OR egresados) AND (qualidade OR calidad OR quality) AND ("graduação em enfermagem" OR } \\
\text { "undergraduate nursing" OR "bacharelado em enfermagem" OR "bachillerato en enfermería") educação em enfermagem" (20\$) }\end{array}$ \\
\hline 8 & $\begin{array}{r}\text { (instrumento OR } \\
\text { student OR egresac } \\
\text { OR "b }\end{array}$ \\
\hline & (questionário \\
\hline
\end{tabular}


realizada na Biblioteca Virtual em Saúde, 5 (2,6\%) artigos do total de 191 enquadraram-se aos critérios de inclusão. Na busca realizada na Biblioteca Virtual de Educação em Ciências da Saúde, nenhum artigo se enquadrou aos critérios de inclusão (Tabela 1).

Neste eixo temático, apreendeu-se que na maioria dos artigos há predomínio da visão tecnicista de educação superior em Enfermagem e, por consequência, da visão tecnicista acerca do conceito de qualidade da educação superior em Enfermagem. Nota-se o enfoque ao desenvolvimento das competências técnico-científicas, não havendo menção à importância de uma formação pautada pelo desenvolvimento das competências atitudinais/comportamentais.

O predomínio da ocorrência de artigos internacionais permite observar que o número de publicações no Brasil acerca da qualidade da educação superior especificamente no âmbito da enfermagem ainda é escasso se comparado aos demais países. Embora as realidades e contextos dos países de publicação sejam distintos da realidade brasileira, muitos aspectos coincidem e podem representar tendências, que em alguns casos, são de abrangência mundial e que extrapolam as fronteiras impostas pelas diferenças culturais e econômicas. Por isso, optou-se por incluir tais produções na amostra de artigos (Quadro 3).

No eixo temático "Percepção de egressos acerca da qualidade da educação superior em Enfermagem”, a busca realizada na Biblioteca Virtual em Saúde demonstrou que dos 60 artigos reportados pela busca $10(16,6 \%)$ enquadraram-se aos critérios de inclusão. Na Biblioteca Virtual de Educação em Ciências da Saúde, 7 (4,5\%) dos 154 artigos enquadraram-se aos critérios de inclusão. Diante disto, 17 artigos compuseram a amostra, conforme demonstrados na Tabela 2.

A partir da leitura e análise das produções observam-se os seguintes pontos de convergência: necessidades de melhoria da infraestrutura das IES pesquisadas, de dinamização das práticas docentes, de desenvolvimento das competências gerenciais e de liderança dos egressos, de superação do modelo hospitalocêntrico e do enfoque à saúde pública, da interdisciplinaridade, de dirimir a dicotomia entre teoria e prática, bem como entre teoria e realidade social, preparando profissionais que atendam às demandas da população. No que se refere ao método, a maioria dos estudos optou pela entrevista com roteiro semiestruturado ou por questionário semiestruturado, como técnicas de coleta de dados. Concluiu-se que apesar de haver artigos concernentes ao tema Percepção de egressos acerca da qualidade da educação superior em Enfermagem, os instrumentos utilizados restringiam-se ao microcontexto das IES pesquisadas, não se observando a existência de instrumento validado e aplicável à multiplicidade de cursos de graduação em Enfermagem ofertados em nosso país. Além disso, verificou-se que os instrumentos focalizaram determinados aspectos em detrimento de outros, inviabilizando a avaliação do curso como um todo integrado e consoante às DCN do curso de graduação em Enfermagem (Quadro 4).

\section{Resultados da Pesquisa Documental}

De acordo com dados disponíveis no site do e-MEC, em 2014, no município de São Paulo havia 33 cursos de graduação em Enfermagem, dentre os quais apenas $7(21,21 \%)$ disponibilizavam seus PPP nos sites das respectivas instituições. Devido ao fato de duas IES utilizarem-se do mesmo PPP, pois apesar de possuírem CNPJ diferentes, são campus de uma mesma IES, optamos por considerar na análise um total de 6 IES e seus 6 respectivos PPP.

As IES foram intituladas como IES 1, IES 2, IES 3, IES 4, IES 5 e IES 6 e os PPP como PPP 1, PPP 2, PPP 3, PPP 4, PPP 5 e PPP 6, visando à preservação da confidencialidade dos dados.

As categorias administrativas das IES foram representadas por 1 (16,6\%) IES Federal; 1 (16,6\%) IES Estadual; 4 (66,6\%) IES privadas. No que se refere à organização acadêmica, $4(66,6 \% \%)$ IES são Universidades; 1 (16,6\%) IES é faculdade; 1 (16,6\%) IES é centro universitário.

A análise demonstrou que 4 (66,6\%) PPP incluíram em sua redação o item "Integração entre teoria e prática"; o item "incentivo à pesquisa" foi explicitado em 5 (83,3\%) PPP. Em contrapartida, a menção ao uso de metodologias ativas e da avaliação formativa esteve presente em apenas 2 (33,3\%) dos PPP. A adoção de estratégias inovadoras de avaliação do processo ensino-aprendizagem, tais como o portfólio, foi observada em apenas 1 dos PPP (16,6\%). Os aspectos como "interdisciplinaridade", "aprendizagem significativa" e "desenvolvimento de competências e habilidades" estiveram presentes em 4 PPP (66,6\%). Em 5 PPP (83,3\%) não foi citado o tipo de relação professor-aluno preconizado para os cursos, tampouco a menção à relação

Tabela 1: Resultados da Pesquisa Bibliográfica do eixo temático "Avaliação da qualidade da educação superior em Enfermagem”, realizada por meio das Estratégias de busca na Biblioteca Virtual em Saúde e na Biblioteca Virtual de Educação em Ciências da Saúde. Brasil, 2014

\begin{tabular}{|l|c|c|c|c|}
\hline Estratégia de busca & \multicolumn{2}{|c|}{ Biblioteca virtual em saúde } & \multicolumn{2}{c|}{ Biblioteca virtual de educação em ciências da saúde } \\
\hline (Quadro 1) & Resultados & Produções selecionadas & Resultados & Produções selecionadas \\
\hline Estratégia 1 & 83 & 4 & 5 & 0 \\
\hline Estratégia 2 & 78 & 0 & 0 & 0 \\
\hline Estratégia 3 & 0 & 0 & 5 & 0 \\
\hline Estratégia 4 & 14 & 1 & 0 & 0 \\
\hline Estratégia 5 & 6 & 0 & 0 & 0 \\
\hline Subtotal & 181 & 5 & 10 & 0 \\
\hline Total: 5 produções & & & & \\
\hline
\end{tabular}


dialógica entre ambos. A formação de profissionais com senso de responsabilidade social, cidadania e com capacidade de intervenção sobre a realidade foi citada em 3 PPP (50\%) e parcialmente citada pela outra metade restante. A formação de indivíduos preparados para a atuação no contexto do SUS esteve presente em
5 PPP (83,3\%). A menção ao pressuposto de que a saúde diz respeito às condições dignas de vida e um direito do cidadão foi observada em 3 PPP (50\%) e parcialmente observada em 2 (33,3\%) deles. A necessidade de que os egressos sejam preparados para atuar profissionalmente compreendendo a natureza humana em

Quadro 3: Dados Bibliográficos, resumo e principais conceitos de qualidade presentes nas publicações do eixo temático "Avaliação da qualidade da educação superior em Enfermagem"

\begin{tabular}{|c|c|}
\hline Artigo & Resumo \\
\hline $\begin{array}{l}\text { Salamonson } \\
\text { et al. } \\
(2010)^{10}\end{array}$ & $\begin{array}{l}\text { Investigação das diferenças entre: a satisfação dos alunos com a equipe de professores titulares } \\
\text { e com a equipe de professores eventuais e diferenças entre as notas de avaliação atribuídas } \\
\text { pelos professores eventuais e as notas atribuídas pelos professores titulares sobre os trabalhos } \\
\text { escritos realizados pelos estudantes. Resultados: comparados aos docentes titulares, os } \\
\text { docentes eventuais obtiveram classificação mais alta quanto à satisfação dos discentes que } \\
\text { cursavam o primeiro e o segundo ano, o que não ocorreu com os estudantes do terceiro ano. } \\
\text { Os professores eventuais atribuíram maiores notas aos estudantes do primeiro e do segundo } \\
\text { ano do que os professores titulares. Os autores afirmam que, à luz da crescente necessidade } \\
\text { de equipes eventuais nos programas de graduação em Enfermagem e tomando por base } \\
\text { os resultados deste e de outros estudos na área, torna-se pertinente o desenvolvimento e a } \\
\text { implementação de estratégias que viabilizem a inclusão de docentes eventuais nos programas } \\
\text { de Bacharelado em Enfermagem, com o intuito de melhor utilizar sua experiência, enquanto se } \\
\text { mantém a equivalência em termos de qualidade de ensino. }\end{array}$ \\
\hline $\begin{array}{l}\text { Garside } \\
\text { et al. } \\
(2009)^{11}\end{array}$ & $\begin{array}{c}\text { Toma-se a avaliação como uma medida da qualidade da formação recebida, bem como } \\
\text { indicativa dos sinais de que o aluno adquiriu ou não as habilidades e conhecimentos } \\
\text { necessários para registro e exercício profissional. }\end{array}$ \\
\hline $\begin{array}{l}\text { Bland \& } \\
\text { Gallagher } \\
(2009)^{12}\end{array}$ & $\begin{array}{l}\text { Pesquisa realizada em uma escola de Enfermagem da Nova Zelândia (NZ) com o objetivo de } \\
\text { avaliar o impacto nos estudantes resultante de mudanças na política de avaliação, que removeu } \\
\text { as oportunidades de reapresentação para trabalhos acadêmicos no terceiro ano do programa } \\
\text { de bacharelado em enfermagem. Embora a maioria dos alunos visse a si mesmos como } \\
\text { prejudicados pela mudança, alguns consideraram ser uma positiva iniciativa para melhoria da } \\
\text { qualidade dos cursos. Na NZ duas condições para que um profissional recém-formado obtenha } \\
\text { o registro profissional são a conclusão, em no máximo } 5 \text { anos após a matrícula inicial, de um } \\
\text { bacharelado aprovado no país e a aprovação no exame comum realizado pelo Conselho Superior } \\
\text { de Enfermagem da Nova Zelândia (CSENZ) com a possibilidade de no máximo } 3 \text { tentativas. } \\
\text { Relata-se que a intencionalidade disto é de proteger os interesses da população por garantir que } \\
\text { recém-formado possui conhecimento que o habilitam à prática. Tais condiçases são parâmetros } \\
\text { legais para a educação em enfermagem na Nova Zelândia, influenciando os educadores de } \\
\text { enfermagem quando elaboram políticas organizacionais para avaliação e reavaliação de estudantes. } \\
\text { A equipe docente também expressou uma maior confiança na formação de qualidade dos alunos } \\
\text { que concluem o programa, devido à extinção das múltiplas possibilidades de realização do exame, } \\
\text { evitando que os alunos sejam aprovados apenas devido às numerosas oportunidades de avaliação. }\end{array}$ \\
\hline
\end{tabular}

Aborda-se o tema Exame Final Clínico Nacional Sueco (EFCS), implementado em 2007, com o intuito de examinar as competências clínicas dos concluintes do Bacharelado em Enfermagem.

O EFCS é um método de avaliação dividido em duas partes: prova escrita e prova prática, realizada à beira leito do paciente. Os respondentes apontaram que o EFCS é um promotor de melhoria no aprendizado e de confirmação das habilidades e do conhecimento adquiridos, bem com um importante meio de assegurar a qualidade do ensino ofertado. Sua natureza abrangente foi percebida como capaz de vincular a educação a um todo integrado e contribuiu para a conscientização dos alunos acerca de sua própria competência clínica.

Estudo que visou comparar as experiências de três grupos de alunos de graduação em enfermagem e sua percepção sobre a qualidade do ensino clínico desenvolvido ao longo do tempo, o que demonstra consonância com a Declaração de Bolonha para desenvolvimento do sistema de qualidade de programas educacionais. Primeiro os estudantes avaliaram sua experiência no ensino clínico após seu primeiro período de educação clínica. A próxima avaliação ocorreu após seu Mendeler segundo período de educação clínica. A avaliação focalizou a supervisão clínica, aprendizagem em et al. $(2013)^{14}$ educação clínica, objetivos de aprendizagem em educação clínica e reflexão em educação clínica. Assim, no ano de 2009 os estudantes suecos avaliaram a percepção Clínica e aprendizagem em educação clínica pior do que os estudantes finlandeses. Já em 2010 os estudantes finlandeses avaliaram a Percepção Clínica pior do que os estudantes suecos. De acordo com os autores, as razões para as variações de resultados entre os anos e entre os países devem ser investigadas mais profundamente. Para eles, também é evidente que a formação clínica prática deve ser desenvolvida em cooperação com as faculdades e equipes atuantes na educação clínica.
Conceitos de qualidade presentes na publicação

Não há menção ao conceito de qualidade da educação superior Constata-se a ênfase ao corpo docente como elemento fundamental para a qualidade.

Não se aborda o conceito de qualidade, sendo que o foco são os métodos de avaliação e esta como uma medida da qualidade da formação recebida.

Aborda-se a o tema controle e regulação da qualidade por meio das políticas de avaliação, vigentes no país.

Nota-se que na Suécia há ênfase ao desenvolvimento das competências clínicas, subentendendo que a aquisição de tais atributos por parte dos egressos equivaleria a assegurar que obtiveram uma formação considerada de qualidade.

Observa-se a tendência a focalizar a qualidade da educação clínica e a percepção dos alunos acerca disto, em detrimento dos demais aspectos envolvidos na formação em Enfermagem. Ademais, não se aborda a concepção acerca da qualidade de educação superior nem no âmbito geral, tampouco no âmbito específico da enfermagem. 
Tabela 2: Resultados da Pesquisa Bibliográfica do eixo temático "Percepção de egressos acerca da qualidade da educação superior em Enfermagem", realizada por meio das Estratégias de busca na Biblioteca Virtual em Saúde e na Biblioteca Virtual de Educação em Ciências da Saúde. Brasil, 2014

\begin{tabular}{|l|c|c|c|c|}
\hline Estratégia de busca & \multicolumn{2}{|c|}{ Biblioteca virtual em saúde } & Biblioteca virtual de educação em ciências da saúde \\
\hline (Quadro 2) & Resultados & Produções selecionadas & Resultados & Produções selecionadas \\
\hline Estratégia 6 & 17 & 0 & 30 & 0 \\
\hline Estratégia 7 & 8 & 0 & 12 & 0 \\
\hline Estratégia 8 & 0 & 0 & 2 & 0 \\
\hline Estratégia 9 & 35 & 10 & 110 & 7 \\
\hline Subtotal & 60 & 10 & 154 & 7 \\
\hline Total: 17 produções & & & & \\
\hline
\end{tabular}

Quadro 4: Dados Bibliográficos, trajetória metodológica e principais conclusões das publicações do eixo temático "Percepção de egressos acerca da qualidade da educação superior em Enfermagem"

\begin{tabular}{|c|c|c|}
\hline $\begin{array}{l}\text { Artigo/ } \\
\text { Dissertação }\end{array}$ & Trajetória Metodológica dos estudos & Principais resultados/conclusões \\
\hline $\begin{array}{l}\text { Carrijo et al. } \\
(2007)^{15}\end{array}$ & $\begin{array}{l}\text { Métodos: entrevista semiestruturada; } \\
\text { "Bola de Neve" (os sujeitos indicam outros } \\
\text { possíveis sujeitos e assim, sucessivamente, } \\
\text { até que se atinja o "ponto de saturação", ou } \\
\text { seja, os participantes começam a repetir } \\
\text { as respostas dadas pelos participantes } \\
\text { anteriores). }\end{array}$ & $\begin{array}{l}\text { Percepção geral dos Egressos: Boa ou ótima avaliação sobre o curso. } \\
\text { Sugestões: melhoria da infraestrutura, dinamização no trabalho de alguns } \\
\text { docentes, ampliação de vagas em pesquisa, estratégias de ensino-aprendizagem } \\
\text { e encontros entre egressos para relatos da realidade do mercado de trabalho. }\end{array}$ \\
\hline $\begin{array}{l}\text { Carvalho } \\
(2011)^{16}\end{array}$ & $\begin{array}{l}\text { Questionário semiestruturado contendo } \\
\text { três eixos: características socioeconômicas, } \\
\text { escolha profissional e formação, inserção e } \\
\text { expectativa profissional. }\end{array}$ & $\begin{array}{c}\text { De maneira geral, demonstrou-se que foi importante a contribuição do curso } \\
\text { na formação dos enfermeiros, graduando profissionais supostamente mais } \\
\text { bem preparados para as novas exigências do mundo do trabalho. A opinião } \\
\text { dos egressos deflagrou reflexões e posteriores mudanças no currículo, que } \\
\text { passou a ser integrado. }\end{array}$ \\
\hline $\begin{array}{l}\text { Jesus et al. } \\
(2013)^{17}\end{array}$ & Entrevistas semiestruturadas & $\begin{array}{l}\text { Conclusões: Aspectos importantes para a formação são o desenvolvimento de } \\
\text { competências para a liderança, gestão de pessoas, relações interpessoais, } \\
\text { o preparo para a docência durante a graduação e formação voltada para a } \\
\text { realidade prática. }\end{array}$ \\
\hline $\begin{array}{l}\text { Martinéli } \\
\text { et al. }(2011)^{18}\end{array}$ & $\begin{array}{l}\text { Questionário com perguntas abertas e } \\
\text { fechadas para avaliar a percepção de } \\
\text { egressos sobre dois currículos distintos } \\
\text { (currículo mínimo e currículo vigente) de um } \\
\text { curso de graduação em Enfermagem. }\end{array}$ & $\begin{array}{l}\text { Currículo vigente: os egressos destacaram como ponto fraco em sua formação o } \\
\text { maior enfoque na área hospitalar, em detrimento da área de saúde pública. } \\
\text { Em ambos os currículos, os egressos consideraram como pontos fortes de sua } \\
\text { formação a continuidade do aprendizado, da educação permanente por meio de } \\
\text { cursos de pós-graduação lato sensu. }\end{array}$ \\
\hline $\begin{array}{l}\text { Meira \& } \\
\text { Kurcgant } \\
(2008)^{19}\end{array}$ & $\begin{array}{l}\text { Entrevista com roteiro semiestruturado: } \\
\text { caracterização dos sujeitos; o contexto de } \\
\text { atuação profissional; a percepção quanto ao } \\
\text { processo de formação e sugestões para a } \\
\text { melhoria do currículo. }\end{array}$ & $\begin{array}{l}\text { Resultados: necessidade de o programa de ensino reforçar o desenvolvimento de } \\
\text { competências ético-políticas; de superar o modelo de ensino hospitalocêntrico; } \\
\text { de promover pesquisas que atendam às demandas de saúde da comunidade; } \\
\text { contextualizar-se de acordo com as políticas públicas de saúde; adotar a } \\
\text { interdisciplinaridade na distribuição dos conteúdos e da carga horária; fortalecer } \\
\text { também a formação de competências específicas, principalmente, as atinentes à } \\
\text { gestão em enfermagem. }\end{array}$ \\
\hline $\begin{array}{l}\text { Meira \& } \\
\text { Kurcgant } \\
(2009)^{20}\end{array}$ & $\begin{array}{l}\text { Entrevista semiestruturada; buscou-se } \\
\text { conhecer a percepção dos egressos } \\
\text { de enfermagem acerca do ensino de } \\
\text { administração. }\end{array}$ & $\begin{array}{c}\text { Necessidade de: aumento da carga horária das disciplinas destinadas à formação } \\
\text { de competências administrativas, de competências ético-políticas; conteúdos } \\
\text { mais abrangentes; estratégias diversificadas; a articulação entre ensino, pesquisa } \\
\text { e extensão; estágios mais precoces; os conteúdos de administração devem } \\
\text { possuir interlocução com as demais disciplinas. }\end{array}$ \\
\hline $\begin{array}{l}\text { Nunes et al. } \\
(2011)^{21}\end{array}$ & $\begin{array}{l}\text { Entrevista semiestruturada; análise por meio } \\
\text { da fenomenologia. }\end{array}$ & $\begin{array}{l}\text { Aspectos positivos da formação: capacitação para reconhecer as necessidades } \\
\text { dos usuários; convicç̃̃es acerca da importância de agir em prol do ser humano; } \\
\text { fundamentos científicos; o reconhecimento de que as habilidades práticas são } \\
\text { adquiridas por realizações contínuas, já os valores e os outros conhecimentos } \\
\text { são construídos ao longo do tempo, por meio do exercício da profissão; saber } \\
\text { relacionar o gerenciamento e o cuidado como aprendizado concreto e aplicável. } \\
\text { Lacunas: distanciamento entre o que é ensinado e a realidade social, na qual } \\
\text { devem ser aplicados os conhecimentos adquiridos (atitudes de como lidar com } \\
\text { o paciente que não eram aplicáveis a determinados contextos); divergência } \\
\text { entre os docentes e os profissionais assistenciais; o longo período de exercício } \\
\text { profissional desprovido do estímulo a atualizações contínuas e de novas buscas } \\
\text { acarreta o declínio na qualidade dos cuidados, a automação, o empobrecimento } \\
\text { dos argumentos e da reflexão acerca das práticas profissionais. }\end{array}$ \\
\hline $\begin{array}{l}\text { P"uschel } \\
\text { et al. }(2009)^{22}\end{array}$ & $\begin{array}{l}\text { Questionário semiestruturado (dados } \\
\text { socioeconômicos, conhecimento de } \\
\text { idiomas, ano e tempo de conclusão do } \\
\text { curso, realização de pós-graduação, } \\
\text { inserção profissional. }\end{array}$ & $\begin{array}{l}\text { As facilidades: o reconhecimento e renome da instituição de formação; terem sido } \\
\text { indicados para o emprego e o fato de possuírem o perfil e a postura adequados. } \\
\text { As dificuldades: serem recém-formados e possuírem baixa experiência prática; } \\
\text { não possuírem pós-graduação; e dificuldades em processos seletivos. }\end{array}$ \\
\hline
\end{tabular}


Quadro 4: Continuação

\begin{tabular}{|c|c|c|}
\hline $\begin{array}{l}\text { Artigo/ } \\
\text { Dissertação }\end{array}$ & Trajetória Metodológica dos estudos & Principais resultados/conclusões \\
\hline $\begin{array}{l}\text { Souza et al. } \\
(2012)^{23}\end{array}$ & Questionário & $\begin{array}{l}\text { As maiores contribuições do curso foram para o desenvolvimento das } \\
\text { competências relacionadas aos princípios éticos e legais da profissão, para atuar } \\
\text { na assistência de Enfermagem e atuar utilizando Processo de Enfermagem; } \\
\text { as menores contribuições foram para o desenvolvimento das competências } \\
\text { relacionadas ao ensino e à pesquisa. De maneira geral, demonstrou-se que foi } \\
\text { importante a contribuição do curso, graduando profissionais supostamente mais } \\
\text { bem preparados para as novas exigências do mundo do trabalho. }\end{array}$ \\
\hline $\begin{array}{l}\text { Zborowski } \\
\text { et al. }(2009)^{24}\end{array}$ & $\begin{array}{l}\text { Questionário semiestruturado com } \\
\text { possibilidade de justificar a resposta. }\end{array}$ & Conclusão: boa inserção no mercado de trabalho \\
\hline $\begin{array}{l}\text { Colenci et al. } \\
(2012)^{25}\end{array}$ & Discurso do Sujeito Coletivo & $\begin{array}{l}\text { Lacunas: falta de conhecimento sobre gerência; insuficiência de estágios e carga } \\
\text { horária para o desenvolvimento das habilidades necessárias à assistência; baixo } \\
\text { incentivo à pesquisa. } \\
\text { Necessidade de: desenvolvimento de competências nas quatro dimensões do } \\
\text { cuidar: gerência, assistência, educação e pesquisa; adoção de um modelo de } \\
\text { formação que coadune com as necessidades da sociedade; avaliação contínua } \\
\text { para proposição de melhorias. }\end{array}$ \\
\hline $\begin{array}{l}\text { Higa et al. } \\
(2013)^{26}\end{array}$ & $\begin{array}{c}\text { Avaliação, por meio da Triangulação das } \\
\text { abordagens quantitativa e qualitativa, } \\
\text { da percepção de egressos do curso de } \\
\text { graduação em Enfermagem da FAMEMA } \\
\text { sobre a problematização e a aprendizagem } \\
\text { baseada em problemas. }\end{array}$ & $\begin{array}{l}\text { Curso tem obtido êxito em desvencilhar-se da formação de cunho tecnicista, } \\
\text { cedendo espaço à Aprendizagem Significativa, bem como à formação que prima } \\
\text { pela autonomia, pelo desenvolvimento do saber, saber ser e saber fazer e pela } \\
\text { construção do conhecimento, condizentes com as DCN, com o SUS e com o } \\
\text { mundo do trabalho. }\end{array}$ \\
\hline $\begin{array}{l}\text { Meira } \\
(2007)^{27}\end{array}$ & Entrevista semiestruturada & $\begin{array}{c}\text { Apontou-se a necessidade de que se invista em uma educação que desenvolva } \\
\text { as competências ético-políticas e que haja uma contextualização com as políticas } \\
\text { públicas de saúde, promovendo a extensão universitária e o atendimento às } \\
\text { demandas da população; sugere-se ainda que se privilegie a interdisciplinaridade } \\
\text { e remanejamento da carga horária, de maneira que sejam enfatizados conteúdos } \\
\text { que viabilizem o desenvolvimento das competências específicas à enfermagem, } \\
\text { tais como administração e liderança em enfermagem. }\end{array}$ \\
\hline $\begin{array}{l}\text { Meira \& } \\
\text { Kurcgant } \\
(2009)^{28}\end{array}$ & $\begin{array}{c}\text { Pesquisa bibliográfica sobre avaliação } \\
\text { educacional }\end{array}$ & $\begin{array}{l}\text { Foi baixo o quantitativo de produções científicas acerca da perspectiva de egressos } \\
\text { como um importante indicador da avaliação institucional. No entanto, observou-se } \\
\text { que os estudos demonstraram a importante contribuição destes sujeitos ao } \\
\text { avaliarem seu processo formativo, destacando-se aspectos como necessidade } \\
\text { de maior investimento em pesquisa; necessidade de incentivo aos projetos de } \\
\text { extensão universitária, possibilitando intercâmbio com a comunidade; premência } \\
\text { de adequação do currículo às demandas profissionais; importância de aumentar a } \\
\text { carga horária de estágio e de propiciar maior integração entre teoria e prática }\end{array}$ \\
\hline $\begin{array}{l}\text { Meira \& } \\
\text { Kurcgant } \\
(2013)^{29}\end{array}$ & Entrevista semiestruturada & $\begin{array}{l}\text { Identificou-se a relevância dos seguintes aspectos necessários ao desenvolvimento } \\
\text { das competências sócio-políticas: compromisso com a aprendizagem permanente; } \\
\text { raciocínio crítico; valores; senso de missão; postura ética no relacionamento } \\
\text { multiprofissional; a importância do papel dos docentes na viabilização ou no } \\
\text { insucesso do desenvolvimento destas competências. A educação na área da } \\
\text { saúde cumpre sua missão quando prepara profissionais capazes de participar da } \\
\text { transformação da realidade da sociedade na qual se insere. } \\
\text { o curso pesquisado no estudo caminha nesta direção, mas necessita propiciar } \\
\text { maior vivência da realidade, o que instigaria os estudantes a refletir sobre o } \\
\text { contexto ético-político da assistência à saúde em que se inserem. }\end{array}$ \\
\hline $\begin{array}{l}\text { Munari et al. } \\
(2008)^{30}\end{array}$ & Entrevistas semiestruturadas & $\begin{array}{l}\text { Pesquisou-se como os egressos de um curso de graduação em enfermagem } \\
\text { utilizam o conhecimento gerado pelo modelo de educação de laboratório. } \\
\text { Constatou-se que tal modelo propicia o fortalecimento pessoal e a compreensão } \\
\text { do trabalho coletivo, possibilitando aos estudantes a oportunidade de vivenciar os } \\
\text { diversos papéis que lhes serão requeridos pela futura prática profissional. }\end{array}$ \\
\hline $\begin{array}{l}\text { Souza et al. } \\
(2006)^{31}\end{array}$ & Questionário semiestruturado. & $\begin{array}{l}\text { Conclui-se que o perfil profissional dos respondentes condizia com o almejado } \\
\text { pelo currículo, ou seja, enfermeiros crítico-reflexivos e preparados para os } \\
\text { desafios e demandas representados pelo mundo do trabalho. }\end{array}$ \\
\hline
\end{tabular}

suas diversas dimensões e fases evolutivas esteve presente em 5 $(83,3 \%)$ dos PPP. Da mesma maneira, 5 (83,3\%) PPP mencionaram os seguintes itens: preparo profissional para atuar nos diferentes níveis de atenção; profissionais generalistas; indivíduos crítico-reflexivos e com competência gerencial; tomada de decisão e trabalho em equipe. Apenas os itens "profissionais com senso de ética" e "profissionais preparados para o reconhecimento dos perfis epidemiológicos das populações" foram citados unanimemente nos 6 (100\%) PPP.
De acordo com a literatura científica, recomenda-se que o PPP não deva se constituir em uma imposição, mas sim em um documento que expresse a identidade da IES e, por isso, deve ser fruto de uma construção coletiva da qual participam os docentes e a equipe administrativa, bem como os discentes, familiares e a comunidade, tendo como foco a melhoria das práticas pedagógicas, transformando concepções em ações ${ }^{32}$. No entanto, nos PPP analisados, não houve menção à participação dos discentes, egressos ou até mesmo da comunidade na elaboração destes documentos, o 
que pode comprometer a qualidade da educação ofertada, já que o principal objeto ao qual se destina, ou seja, os estudantes e egressos, não são partícipes desta construção.

Discutem-se, a seguir, alguns trechos dos PPP que coadunam com o objeto da presente pesquisa e que se aproximam dos aspectos considerados relevantes para a qualidade dos cursos de graduação em Enfermagem.

- PPP 1: Um trecho versa sobre a necessidade de que o profissional do mundo atual não desenvolva apenas as habilidades e competências específicas da profissão na qual se formou, mas que também compreenda e atue de forma sustentável, em consonância às políticas públicas de sustentabilidade. Assim, o curso oferece uma disciplina com enfoque a este tema. Um diferencial importante deste PPP foi a menção à adoção de uma Política de Atendimento ao Estudante com deficiência, que prevê o desenvolvimento de ações que propiciem o acesso, a permanência e a qualidade da educação ofertada a estes estudantes. Tal política se constitui em algo imprescindível à qualidade das IES e de seus cursos, sendo lamentavelmente, pouco observada na prática das IES.

- PPP 2: O documento é intitulado como Projeto, mas não se apresenta com estrutura esperada para tal tipo de documento, faltando, por exemplo, itens como a contextualização do curso, origem da IES, dentre outros aspectos. O documento trata, de maneira sucinta, a missão, os objetivos gerais e específicos do curso, o perfil do egresso e a estrutura curricular. Destacam-se os trechos concernentes à formação de profissionais com consciência de seu papel social e capazes de analisar criticamente o contexto onde se inserem. Além disso, cita-se que além da necessidade de desenvolverem as competências e habilidades técnico-científicas, os egressos precisam também desenvolver as competências de cunho ético-político-sociais-educativas, bem como exercer sua profissão de maneira reflexiva, crítica e criativa, sendo capazes de se apropriar do conhecimento e de recriá-lo.

- PPP 3: O documento é intitulado como Projeto Pedagógico, mas assemelha-se mais a um folder de divulgação e publicidade do curso. Apresenta um sucinto resumo acerca dos objetivos do curso, perfil do egresso e os principais campos de estágio. Dentre os trechos que se aproximam dos aspectos considerados relevantes para a qualidade do curso destacam-se os seguintes, referentes ao perfil do egresso: ser capaz de realizar uma leitura crítica e contextualizada da realidade de nosso país, comprometendo-se com reconstrução da sociedade; problematizar as políticas de saúde e interpretar os perfis epidemiológicos das populações; assumir compromisso ético-político que vise à melhoria das condições de saúde da população, sabendo da realidade perversa da estrutura social de nosso país; reconhecer seu papel de sujeito histórico, interferindo na dinâmica institucional; utilizar de maneira crítica o aparato tecnológico disponível.

- PPP 4: Cita-se o intuito de formar profissionais socialmente responsáveis, empreendedores e transformadores da realidade contemporânea. Destaca-se também o trecho que versa sobre a avaliação do aprendizado, que é realizada por meio de prova de competência, contemplando os conteúdos abordados tanto no semestre vigente quanto em semestres anteriores. Apesar de haver a menção apenas a um tipo de instrumento de avaliação (prova) e de não ter sido mencionada a adoção de métodos avaliativos inovadores e condizentes com a linha formativa, ao menos focaliza-se uma avaliação das competências desenvolvidas e, aparentemente, de maneira processual, pois aborda tanto os temas do semestre em curso quanto os temas dos semestres já cursados. Na redação, observa-se que é necessário que se garanta o desenvolvimento não somente das competências relacionadas à formação específica, mas também a inserção no debate contemporâneo mais amplo, envolvendo aspectos culturais, econômicos, sociais e o conhecimento sobre o desenvolvimento humano.

- PPP 5: Menciona-se o uso do portfólio como estratégia para o acompanhamento do processo de ensino-aprendizagem, bem como método de avaliação do estágio supervisionado, o que demonstra a adoção da avaliação em sua vertente formativa. O documento preconiza que o estágio curricular supervisionado deve desenvolver no estudante as competências nas dimensões assistencial, educativa, investigativa e gerencial. Dentre outros trechos do documento, merece menção o item que versa a respeito do arcabouço teórico sobre o qual foi estruturado o curso de graduação em enfermagem, que pressupõe a formação como algo que não é a mera transmissão de conhecimento, mas sim como um processo que requer a interação entre docentes e discentes com o movimento de ação-reflexão-ação, vislumbrando a resolução de situações-problema.

- PPP 6: Relata-se que o processo de ensino-aprendizagem fundamenta-se na metodologia dialética, o que demanda do docente nova e ampliada concepção acerca de sujeito, conhecimento e processo ensino-aprendizagem, considerando o aluno como alguém com papel ativo sobre este processo. Reconhece-se que ainda há no curso o predomínio do ensino tradicional, mas que a equipe docente possui a intencionalidade de implementar melhorias no processo ensino-aprendizagem, por meio do investimento em sua formação pedagógica e de mudanças curriculares. Outro trecho que merece destaque versa sobre a extensão universitária, cuja importância reside na participação da sociedade sobre a Universidade, o que possibilita a articulação entre o saber acadêmico (sistematizado) e o saber popular e tácito, produzido no cotidiano. Esta integração viabiliza a produção de novos conhecimentos, advindos do confronto com a realidade local. O documento afirma que tal processo permite a democratização do saber acadêmico, que retorna à universidade burilado, validado e enriquecido pelo confronto com a prática. Ressalta-se que a extensão universitária deve ser realizada em articulação com os serviços de saúde, devendo também promover a autonomia de todos os envolvidos, tornando-os partícipes e evitando-se qualquer forma de assistencialismo e de dependência. 
Apesar de amplamente difundido que os PPP deveriam ser disponibilizados para consulta pública, tal prática ainda está aquém do necessário, conforme salientado anteriormente. Ademais, apesar da preconização de que a elaboração dos PPP deve ter como arcabouço teórico os pressupostos constantes das DCN, a presente análise permitiu apreender que alguns dos documentos analisados ainda se furtam a esta prática, o que se constitui em algo alarmante e digno de reformulação. Tal constatação suscita a reflexão acerca da qualidade dos cursos, no sentido de que, tomando por base que ainda que os itens preconizados pelas DCN estejam presentes nos PPP dos cursos, é sabido que são inúmeros os desafios enfrentados para que as idealizações e planejamentos transcendam a mera postulação teórica e passem a integrar, de fato, as práticas dos cursos ofertados.

A este já conhecido fator, soma-se o agravante de que se nem ao menos nos PPP consta a menção à intenção de que os cursos se adequem aos pressupostos das DCN, como assegurar que eles seriam aplicados à prática? Em outras palavras, se até mesmo as IES que em seus documentos se comprometem a cumprir minimamente os postulados das DCN não conseguem assegurar que não esbarrarão em entraves para tornar tangíveis na prática tais postulados, o que diríamos daquelas IES que não declaram a intenção de seguir tais postulados ao menos em teoria?

Em que pesem as lacunas elencadas, a maior parte das competências preconizadas nas DCN do curso de Graduação em Enfermagem foi ainda que de maneira incipiente, citada nos documentos analisados.

Diante de todo o exposto, é possível estabelecer algumas intersecções entre os achados da pesquisa bibliográfica e os achados da pesquisa documental. Assim, na literatura pesquisada, cita-se a necessidade de dinamização das práticas docentes, o que coaduna com a lacuna observada nos PPP analisados, que além de não citarem o tipo de relação professor-aluno esperado, também não mencionam a adoção de metodologias ativas e de avaliação formativa, que são componentes diretamente relacionados às práticas docentes, demonstrando, por conseguinte, a premência de que a formação destes profissionais seja objeto de pesquisas e de propostas de melhoria da qualidade da educação superior.

Ademais, a despeito do atual panorama de progressiva ascensão do modelo biopsicossocial, em detrimento do modelo biomédico, ainda se observam reflexos deste último, pois apesar de os PPP mencionarem a formação de profissionais generalistas e por consequência, com uma visão pautada pela integralidade da saúde, o confronto com a literatura demonstra um predomínio do modelo hospitalocêntrico como parte do relato de egressos.

A presente análise não pretendeu esgotar a discussão acerca da literatura científica sobre qualidade da educação superior em Enfermagem, tampouco acerca dos referenciais de qualidade adotados na elaboração dos PPP, mas poderá suscitar a necessidade de se focalizar melhor tais itens quando o que se pretende é avaliação da qualidade da educação superior em Enfermagem e de suas demandas por melhorias.

\section{AGRADECIMENTOS}

À bibliotecária Andreia da Silva Santos pelo auxílio na elaboração das estratégias de busca bibliográfica.

\section{REFERÊNCIAS}

1. Chaves VLJ, Amaral NC. Políticas de financiamento da educação superior no Brasil: o incentivo à privatização. In: Jezine E; Bittar M. Políticas de educação superior no Brasil: expansão, acesso e igualdade social. João Pessoa: Editora da UFPB; 2013

2. Silva Júnior JR, Sguissardi V. A nova lei de educação superior: fortalecimento do setor público e regulação do privado/mercantil ou continuidade da privatização e mercantilização do público? Rev Bras Educ. 2005;(29):5-27

http://dx.doi.org/10.1590/S1413-24782005000200002

3. Tavares MGM, Meneghel SM, Robl F, Barreyro GB, Rothen JC Sousa JV. Políticas de Expansão da Educação Superior no Brasil Pós-LDB/96: desafios para a avaliação. Inter-Ação. 2011;36(1):81-9. http://dx.doi.org/105216/ia.v36i1.15029

4. Saupe R, Alves ED. Contribuição à construção de projetos político-pedagógicos na enfermagem. Rev Latino-Am Enfermagem. 2000;8(2):60-7. http://dx.doi.org/10.1590/S0104-11692000000200010

5. Brito MRF. O SINAES e o ENADE: da concepção à implantação. Avaliação. 2008;13(3):841-50

6. Houaiss A. Dicionário Houaiss da língua portuguesa. Editora Objetiva; 2009

7. Demo P. Qualidade da educação: tentativa de definir conceitos e critérios da avaliação. Est Aval Educ. 1990;(2):11-25. http://dx.doi.org/10.18222/eae00219902389
8. Minayo MCS, Deslandes SF, Cruz Neto O, Gomes R. Pesquisa social: teoria, método e criatividade. 29a ed. Petrópolis: Vozes; 2010

9. Lüdke M, André MEDA. Pesquisa em educação: abordagens qualitativas. São Paulo: Pedagógica e Universitária; 1986.

10. Salamonson Y, Halcomb EJ, Andrew S, Peters K, Jackson D. A comparative study of assessment grading and nursing students' perceptions of quality in sessional and tenured teachers. J Nurs Scholarsh. 2010;42(4):423-9 http://dx.doi.org/10.1111/j.1547-5069.2010.01365.x

11. Garside J, Nhemachena JZ, Williams J, Topping A. Repositioning assessment: giving students the 'choice' of assessment methods. Nurse Educ Pract. 2009;9(2):141-8. http://dx.doi.org/10.1016/j.nepr.2008.09.003

12. Bland M, Gallagher P. The impact of a change to assessment policy on students from a New Zealand school of nursing. Nurse Educ Today. 2009;29(7):722-30. http://dx.doi.org/10.1016/j.nedt.2009.02.015

13. Lilja Andersson $P$, Ahlner-Elmqvist M, Johansson UB, Larsson M Ziegert K. Nursing students' experiences of assessment by the Swedish National Clinical. Nurse Educ Today. 2012;33(5):536-40. http://dx.doi.org/10.1016/j.nedt.2011.12.004

14. MelenderHL,JonsénE, HilliY.Qualityof clinicaleducation-comparison of experiences of undergraduate student nurses in Finland and Sweden. Nurse Educ Pract. 2013;13(4):256-61. http://dx.doi.org/10.1016/j.nepr.2013.01.003 
15. Carrijo CIS,Bezerra ALC, Munari DB, Medeiros $M$ A empregabilidade de egressos de um Curso de Graduação em Enfermagem. Rev Enferm UERJ. 2007;15(3):356-63.

16. Carvalho, LS. Uma antiga profissão do futuro: percepções de enfermeiros sobre sua formação e inserção profissional. Dissertação (Mestrado) - Escola Nacional de Saúde Pública Sergio Arouca, Rio de Janeiro, 2011.

17. Jesus BH, Gomes DC, Spillere LBB, Prado ML, Canever BP. Inserção no mercado de trabalho: trajetória de egressos de um curso de graduação em enfermagem. Esc Anna Nery. 2013;17(2):336-45

http://dx.doi.org/10.1590/S1414-81452013000200019

18. Martinéli DD, Moura CR, Cesarino CB, Beccaria LM, Pinto $\mathrm{MH}$, Paschoal VDA. Avaliação do Currículo da Graduação em Enfermagem por Egressos. Cogitare Enferm. 2011;16(3):524-9.

19. Meira MDD, Kurcgant P. Avaliação da formação de enfermeiros segundo a percepção de egressos. Acta Paul Enferm. 2008;21(4):556-61.

http://dx.doi.org/10.1590/S0103-21002008000400004

20. Meira MDD, Kurcgant P. O ensino de administração na graduação: percepção de Enfermeiros egressos. Texto Contexto Enferm. 2009;18(4):670-9.

21. Nunes DM, Bottan G, Bianchi LB. Manifestações de egressos de um curso de enfermagem. REME Rev Min Enferm. 2011;15(1):97-104

22. Püschel VAA, Inácio MP, Pucci PPA. Inserção dos egressos da Escola de Enfermagem daUSP no mercado de trabalho: facilidades e dificuldades. Rev Esc Enferm USP. 2009;43(3):535-42. http://dx.doi.org/10.1590/S0080-62342009000300006

23. Souza SNDH, Miyadahira AMK. O desenvolvimento de competências no curso de graduação em Enfermagem: percepção de egressos. Cienc Cuid Saúde. 2012; 11(supl):243-50. http://dx.doi.org/10.4025/cienccuidsaude.v11i5.17082
24. Zborowski IP, Jabur MRL, Lúcio DE, Sperandio DB, Dias E. Enfermeiros egressos: expectativas e oportunidades no mercado de trabalho. CuidArte Enferm. 2009;3(1):41-5.

25. Colenci R, Berti HW. Formação profissional e inserção no mercado de trabalho: percepções de egressos de graduação em enfermagem. Rev Esc Enferm USP. 2012;46(1):158-66. http://dx.doi.org/10.1590/S0080-62342012000100022

26. Higa, EFR, Gomes R, Carvalho MHR, Guimarães APC, Taipeiro EF, Marmorato ML, et al. Percepção do egresso de enfermagem sobre a contribuição do curso para o exercício do cuidado. Texto Contexto Enferm. 2013;22(1):97-105. http://dx.doi.org/10.1590/S0104-07072013000100012

27. Meira MDD. Avaliação da Formação do Enfermeiro: Percepção dos Egressos de um Curso de Graduação em Enfermagem. Dissertação (Mestrado) - Escola de Enfermagem da Universidade de São Paulo, São Paulo, 2007.

28. Meira MDD, Kurcgant P. Avaliação de Curso de Graduação segundo Egressos. Rev Esc Enferm USP. 2009,43(2):481-5. http://dx.doi.org/10.1590/S0080-62342009000200031

29. Meira MDD, Kurcgant P. O desenvolvimento de competências ético-políticas segundo egressos de um Curso de Graduação em Enfermagem. Rev Esc Enferm USP. 2013;47(5):1211-8. http://dx.doi.org/10.1590/S0080-623420130000500027

30. Munari DB, Rocha BS, Weirich CF, Medeiros M, Bezerra ALQ, Barbosa MA. O modelo de educação de laboratório como estratégia de Ensino na formação do enfermeiro: percepção dos egressos. Ciênc Cuid Saude. 2008;7(1):89-97.

31. Souza NVDO, Correia LM, Rodrigues BMRD, Pereira AM, Pena DA, Nunes KSM. O enfermeiro e a teoria crítica da Educação: sua inserção no mundo do trabalho. Rev Enferm UERJ. 2006;14(4):506-11.

32. Longhi SRP, Bento KL. Projeto Político-Pedagógico: uma construção coletiva. Rev Divulg Técnico-Científ ICPG. 2006;3(9):173-8. 